\title{
Calcium Influx and Vascular Reactivity in Systemic Hypertension
}

\author{
LOREN P. THOMPSON, PhD, CATHY A. BRUNER, PhD, FRED S. LAMB, BS, \\ CHARLOTTE M. KING, BS, and R. CLINTON WEBB, PhD
}

Numerous studies have focused on functional vascular changes that characterize the hypertensive state. Recent evidence that suggests that increased vascular reactivity in hypertension is due to changes in the delivery of activator $\mathrm{Ca}^{++}$through channels in the cell membrane will be reviewed. The primary evidence supporting this hypothesis comes from studies that characterize the effects of $\mathrm{Ca}^{++}$-free solution and calcium channel blockers on contractile properties of isolated vascular smooth muscle. In the present study, experiments were performed to investigate the role of $\mathrm{Ca}^{++}$influx in vascular contractions produced by interventions that cause membrane depolarization. Isometric tension development in helical strips of carotid arteries from stroke-prone spontaneously hypertensive rats in response to elevated $\mathrm{K}^{+}$and tetraethylammonium chloride was greater than that in carotid arteries from Wistar-Kyoto normotensive rats. The rate of tension development to $\mathrm{K}^{+}$-free solution in carotid arteries from stroke-prone spontaneously hypertensive rats was faster than in Wistar-Kyoto normotensive rat arteries. Contractile responses to all 3 depolarizing interventions were reduced in arterial strips incubated in $\mathrm{Ca}^{++}$-free solution containing the chelator ethylene glycol bis-( $\beta$-aminoethyl ether) $\mathbf{N}, \mathbf{N}, \mathbf{N}^{\prime}, \mathbf{N}^{\prime}$-tetraacetic acid and in arterial strips treated with the $\mathrm{Ca}^{++}$channel blocker verapamil. These results are consistent with the hypothesis that constrictor stimuli that produce membrane depolarization cause an opening of $\mathrm{Ca}^{++}$channels in the plasma membrane that are sensitive to the organic channel blockers. Further, a change in $\mathrm{Ca}^{++}$permeability or membrane depolarizing mechanisms contributes to increased contractile responsiveness in carotid arteries of stroke-prone spontaneously hypertensive rats.

(Am J Cardiol 1987;59:29A-34A) ascular reactivity, defined as the magnitude of the response to a constrictor stimulus, is increased in humans with hypertension and in animal models of hypertension. The response may be measured as a contraction in an isolated vascular segment, as a change in resistance in a perfused vascular bed or as a pressor effect in the intact animal (if cardiac output is unchanged). Increased vascular reactivity in hypertension is due to a combination of 2 separate changes: a

From the Department of Physiology, The University of Michigan Medical School, Ann Arbor, Michigan. This work was supported by grants HL-27020 and HL-18575 from the National Institutes of Health, Bethesda, Maryland. Dr. Thompson was supported by a postdoctoral fellowship from the American Heart Association of Michigan. Dr. Bruner is the recipient of a postdoctoral fellowship from the National Institutes of Health (HL-06968)

Address for reprints: R. Clinton Webb, PhD, Department of Physiology, 7813 Medical Science Building II, The University of Michigan Medical School, Ann Arbor, Michigan 48109. functional alteration in vascular smooth muscle, which results in a greater contraction in response to a given stimulus, and a structural modification of the vascular wall (increased wall to lumen ratio), which causes a greater decrease in vessel radius for a given shortening of vascular smooth muscle cells. Folkow ${ }^{1}$ has reviewed the experimental evidence indicating that structural changes are an adaptive response to increased arterial blood pressure and that these structural changes contribute significantly to the increased vascular reactivity observed in hypertension.

Numerous studies have been performed that investigate functional alterations in vascular smooth muscle from hypertensive animals. ${ }^{2}$ Because the contractile state of vascular smooth muscle varies in proportion to the concentration of $\mathrm{Ca}^{++}$in the cytoplasm, ${ }^{3}$ many investigators have tested the hypothesis that increased vascular reactivity in hypertension is due to increased delivery of activator $\mathrm{Ca}^{++}$through channels in the cell membrane.?-6 This aspect of excitation-contraction coupling has been characterized by measurement of 
contractile responses in isolated vascular preparations under 2 experimental conditions: in the presence and absence of extracellular $\mathrm{Ca}^{++}$, and after treatment with drugs that block membrane channels for $\mathrm{Ca}^{++}$.

Figures 1 and 2 show 2 types of contractile responses that are altered in hypertension; both are dependent on the level of $\mathrm{Ca}^{++}$in the external bathing medium. Isolated arterial strips from 2 kidney, 1 clip $(2 \mathrm{~K}-1 \mathrm{C})$ renal hypertensive rats and normotensive controls were incubated for 10 minutes in $\mathrm{Ca}^{++}$-free solution containing the $\mathrm{Ca}^{++}$chelator EGTA. ${ }^{6}$ After the incubation period, arterial segments from $2 \mathrm{~K}-1 \mathrm{C}$, but not normotensive control rats, contracted in response to $\mathrm{Ca}^{++}$(Fig. 1). The period in $\mathrm{Ca}^{++}$-free solution [ $1 \mathrm{mM}$ EGTA] appears to alter the vascular smooth muscle membrane in strips from hypertensive rats in a way that causes it to become more permeable to $\mathrm{Ca}^{++}$. The magnitude of this "leak" appears to vary with the vessel studied, with the order of greatest to the least leak being aorta, mesenteric artery and tail artery. In addition to a $\mathrm{Ca}^{++}$leak, it appears that specific membrane channels that open in response to receptor activation are changed in the hypertensive state. Tail arteries from stroke-prone spontaneously hypertensive rats (SHRs) contract in an oscillatory manner in response to norepinephrine whereas those from normotensive rats do not (Fig. 2). ${ }^{3}$ The oscillatory contractile activity is caused by an abnormal variation in $\mathrm{K}^{+}$efflux during stimulation with norepinephrine. The altered $\mathrm{K}^{+}$efflux appears to be related to $\mathrm{Ca}^{++}$entry because lowering the concentration of $\mathrm{Ca}^{++}$in the external medium decreases the magnitude of oscillatory activity, ${ }^{7,8}$

Further evidence that supports the hypothesis that altered membrane flux of $\mathrm{Ca}^{++}$contributes to increased vascular reactivity in hypertension is available from studies using calcium channel blockers. ${ }^{7-12}$ Lederballe Petersen et al ${ }^{10}$ have observed that nifedipine caused a more pronounced relaxation of SHR aortic strips contracted with norepinephrine than those from Wistar-Kyoto normotensive rats. Similarly, in humans, calcium channel blockers produce greater depressor effects in hypertensive subjects than in normotensive subjects. ${ }^{12}$ In addition to blocking $\mathrm{Ca}^{++}$influx through membrane channels, these compounds may also inhibit other actions of $\mathrm{Ca}^{++}$at membrane sites. In a recent study in our laboratory, ${ }^{13}$ we observed that elevated $\mathrm{Ca}^{++}$causes relaxation of tail arteries contracted with methoxamine (Fig. 3). The magnitude of relaxation in response to elevated $\mathrm{Ca}^{++}$is less in tail arteries from SHRs compared with those from WistarKyoto normotensive rats. D-600 inhibited the relaxation to elevated $\mathrm{Ca}^{++}$, suggesting that $\mathrm{D}-600$ either blocks $\mathrm{Ca}^{++}$sites that produce membrane stabilization or inhibits transmembrane movement of $\mathrm{Ca}^{++}$that may act intracellularly to stimulate $\mathrm{K}^{+}$efflux and inhibit contraction.

The goal of the current study was to investigate the role of $\mathrm{Ca}^{++}$influx in altered contractile responses to depolarizing stimuli in vascular smooth muscle from stroke-prone SHRs. Three depolarizing interventions were used: elevated $\mathrm{K}^{+}$concentration, $\mathrm{K}^{+}$-free conditions and treatment with the $\mathrm{K}^{+}$channel blocker tetraethylammonium chloride. The role of $\mathrm{Ca}^{++}$influx in contractile responses to membrane depolarization was determined by measuring the responses before and after incubation in $\mathrm{Ca}^{++}$-free solution and in the absence and presence of the calcium channel blocker verapamil.

\section{Methods}

Animals: Stroke-prone SHRs and Wistar-Kyoto normotensive rats (8 of each strain) were obtained from a colony in the Department of Anatomy and Cell Biology at The University of Michigan. The colony was derived from stock supplied by the National Institutes of Health. The rats were 4 to 6 months old at the time of experimentation. Systolic blood pressures were measured in the conscious state by a tail cuff method (pneumatic transducer).
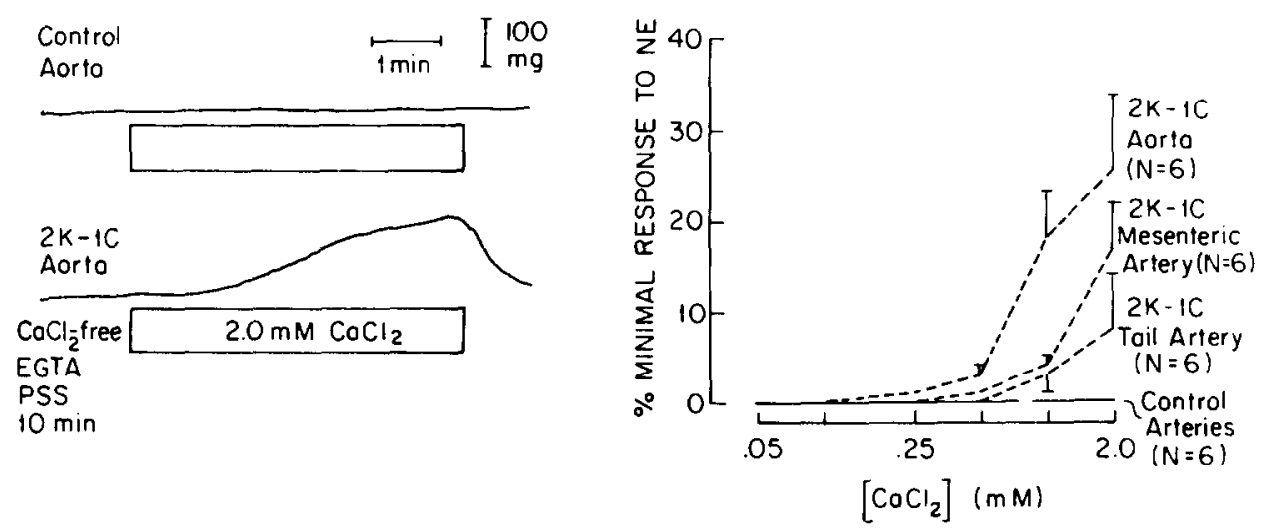

FIGURE 1. Vascular response after exposure to $\mathrm{Ca}^{++}$-free physiologic salt solution (PSS) containing $1.0 \mathrm{mM}$ EGTA. Arterlal segments from 2 kidney, 1 clip $\left(2 \mathrm{~K}-1 \mathrm{C}\right.$ ) hypertensive, but not normotensive, rats contracted in response to $\mathrm{Ca}^{++}$after treatment with $\mathrm{Ca}^{++}-$free PSS, 1.0 mM EGTA (left) Contractile response (expressed as a percentage of the maximal response to norepinephrine) was greatest in aortic strips and least in tail arteries from hypertensive rats; mesenteric arteries were intermedlate in contractile magnilude (right). Values are the mean \pm standard error of the mean for 6 hypertensive and 6 normotensive rats. Reproduced with permission from Martinus Nijhoff. ${ }^{6}$ 
Experimental protocol: Rats were anesthetized with sodium pentobarbital $(50 \mathrm{mg} / \mathrm{kg}$ ) and both carotid arteries were excised and placed in a cold physiologic salt solution. Carotid arteries from stroke-prone SHRs and Wistar-Kyoto normotensive rats were cut into helical strips $(0.8 \mathrm{~mm} \times 10 \mathrm{~mm})$. Vascular strips were mounted on stationary metal bases and suspended in a 50 -ml tissue bath filled with physiologic salt solution maintained at $37^{\circ} \mathrm{C}$. Arterial segments were attached to force transducers (Grass FT.03) for measurement of isometric force and recorded on Grass polygraphs. A constant passive tension of $5 \mathrm{mN}$ was applied to the vascular strips and a 90-minute equilibration period preceded each experiment. The physiologic salt solution was aerated with a mixture of $95 \% \mathrm{O}_{2}$ and $5 \% \mathrm{CO}_{2}$ and its composition (mmol/liter) was as follows: $\mathrm{NaCl}$ (130), $\mathrm{KCl}$ (4.7), $\mathrm{KH}_{2} \mathrm{PO}_{4}$ (1.18), $\mathrm{MgSO}_{4} \cdot 7 \mathrm{H}_{2} \mathrm{O}$ (1.17), $\mathrm{NaHCO}_{3}$ (14.9), $\mathrm{CaCl}_{2}$ (2.5), dextrose (5.5) and $\mathrm{CaNa}_{2}$ EDTA [0.03). $\mathrm{K}^{+}$-free solution was made by the omission of $\mathrm{KCl}$ and equimolar substitution of $\mathrm{NaH}_{2} \mathrm{PO}_{4}$ for $\mathrm{KH}_{2} \mathrm{PO}_{4}$ in the physiologic salt solution.

All experiments were conducted in the presence of phentolamine (Regitine mesylate, CIBA Pharmaceutical Co., $10^{-6} \mathrm{M}$ ) to eliminate vascular effects of norepinephrine that may be released from adrenergic nerve endings by depolarizing stimuli. ${ }^{14}$ Elevations in $\mathrm{K}^{+}$ concentration of the physiologic salt solution were made by addition of appropriate amounts from a concentrated solution of $\mathrm{KCl}(3 \mathrm{M})$.

Three vascular responses were examined in carotid arteries from stroke-prone SHRs and Wistar-Kyoto normotensive rats ( 6 of each): (1) dose-response curve to cumulative addition of $\mathrm{KCl}$ ( 8 to $125 \mathrm{mM}$ ) to the tissue bath, (2) time course of contraction in $\mathrm{K}^{+}$-free physiologic salt solution (120 minutes exposure), and (3) cumulative dose-response curve to tetraethylammonium chloride $\left[3 \times 10^{-4} \mathrm{M}\right.$ to $10^{-1} \mathrm{M}$; Aldrich Chemical Co., Inc.). Vascular strips were exposed to each concentration of tetraethylammonium chloride for 20 minutes and responses were taken to be the peak contractile force at each concentration. Further experiments were performed in arteries from stroke-prone SHRs and Wistar-Kyoto normotensive rats to examine the effects of verapamil and $\mathrm{Ca}^{++}$-free conditions on

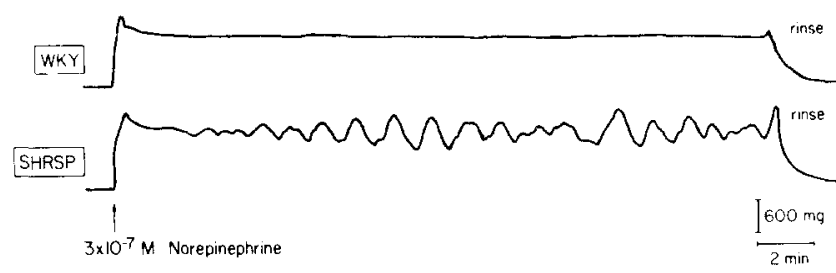

FIGURE 2. Oscillatory contractile responses to norepinephrine in tail arteries from stroke-prone spontaneously hypertensive rats (SHRSP). Norepinephrine $\left(3 \times 10^{-7} \mathrm{M}\right)$ responses in isolated tail artery strips from SHRSP (bottom) are characterized by fluctuations in contractile activity, whereas contractile responses in arterial strips from Wistar-Kyoto (WKY) normotensive rats are maintained. Reproduced with permission from Am J Physiol. ${ }^{7}$ the just described vascular responses. Vascular strips were either incubated in $\mathrm{Ca}^{++}$-free physiologic salt solution containing $1 \mathrm{mM}$ EGTA or exposed to verapamil $\left(10^{-6} \mathrm{M}\right.$; Sigma Chemical Co.) for 5 minutes before the following stimuli: (1) $125 \mathrm{mM} \mathrm{KCl}$, (2) 120 minutes exposure to $\mathrm{K}^{+}$-frec physiologic salt solution and (3) $10^{-1} \mathrm{M}$ tetraethylammonium chloride. Peak contractile responses were analyzed.

To control for variations in strip size, isometric force was converted to tension. First, the area of each carotid artery strip was calculated as the weight of the tissue $(\mathrm{mg})$ divided by the product of density (1.05) and length of the strip at $5 \mathrm{mN}$ passive force $(\mathrm{mm})$. Tension $\left(\mathrm{mN} / \mathrm{mm}^{2}\right)$ was then calculated as isometric force $(\mathrm{mN})$ divided by area $\left(\mathrm{mm}^{2}\right)$.

Statistical analysis: Data are reported as the mean \pm standard error of the mean. For calculation of median effective dose values (concentration that caused a $50 \%$ maximal response) to $\mathrm{KCl}$, contractile responses were expressed as a percentage of the maximal re-
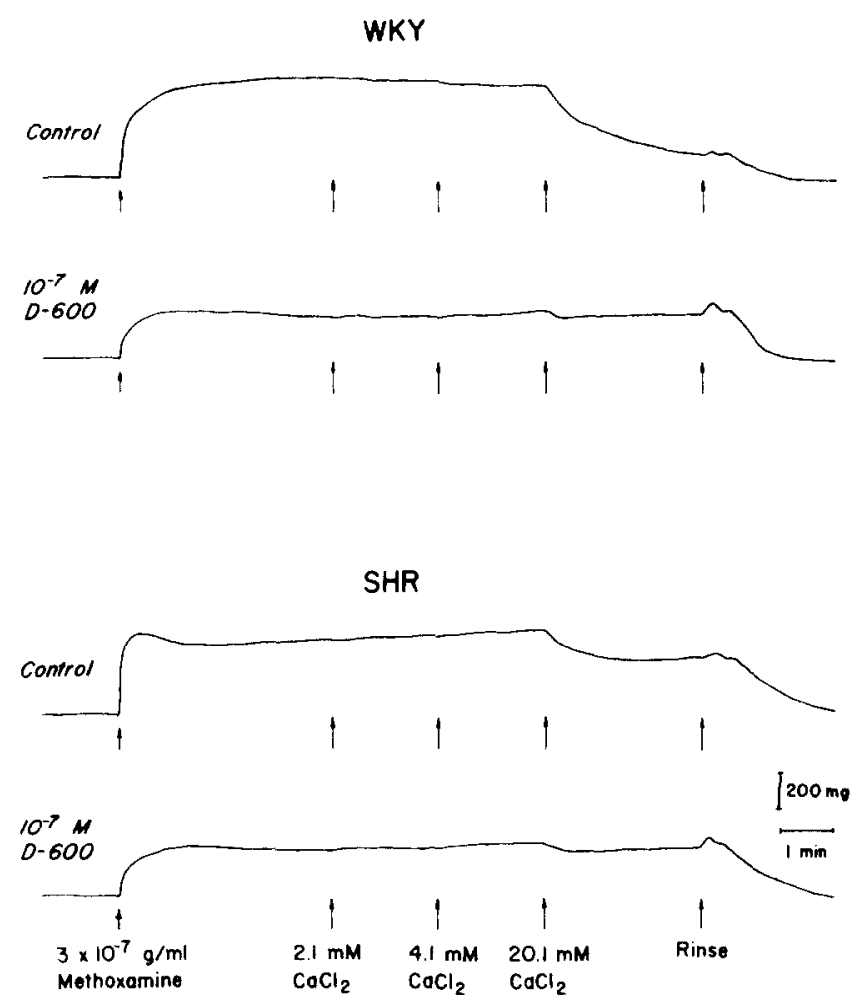

FIGURE 3. D-600 and the membrane stabilizing effect of $\mathrm{Ca}^{++}$. Contractile responses to methoxamine $\left(3 \times 10^{-7} \mathrm{~g} / \mathrm{ml}\right)$ were measured in tail artery strips from spontaneously hypertensive rats (SHR) and Wistar-Kyoto (WKY) normotensive rats in the absence and presence of $10^{-7} \mathrm{M}$ D-600. After contractile responses had reached a plateau, the $\mathrm{Ca}^{++}$concentration of the buffer was raised from $1.6 \mathrm{mM}$ to $4.1 \mathrm{mM}$ and then to $20.1 \mathrm{mM}$. Relaxation responses to $20.1 \mathrm{mM} \mathrm{Ca}^{++}$were less in tail arteries from SHRs compared with that in tail arteries from WKY normotensive rats. This relaxation response is caused by a membrane stabilizing effect of $\mathrm{Ca}^{++}$ and is inhibited by D-600. The magnitude of D-600 inhibition of the $\mathrm{Ca}^{++}$-induced relaxation is less in tail arteries of SHRs compared with WKY normotensive rats strips. Reproduced with permission from Alan R. Liss. ${ }^{13}$ 
sponse and a probit analysis was then performed. Threshold values for contractile responses to tetraethylammonium chloride are defined as the dose of the drug that produced a $5 \mathrm{mN} / \mathrm{mm}^{2}$ response in the tissue, and these values were estimated after graphic representation of dose-response curves. Threshold values are used as an indicator of vascular sensitivity to tetraethylammonium chloride, because this agent did not cause maximal tension development. The rate of contraction in response to $\mathrm{K}^{+}$-free solution is operationally defined as time to half of maximal response. Statistical comparisons between rat groups were performed by Student's $t$ test. A p value of 0.05 was the criterion for statistical significance.

\section{Results}

Animals and tissue preparation: Systolic blood pressures of stroke-prone SHRs $(196 \pm 6 \mathrm{~mm} \mathrm{Hg}, \mathrm{n}=8$ ) were significantly higher than those of Wistar-Kyoto normotensive rats $(118 \pm 3 \mathrm{~mm} \mathrm{Hg}, \mathrm{n}=8, \mathrm{p}<0.05)$. The calculated cross-sectional areas of carotid artery strips from stroke-prone SHRs $\left(0.108 \pm 0.005 \mathrm{~mm}^{2}, \mathrm{n}=16\right)$ did not differ from those of arterial strips from WistarKyoto normotensive rats $\left(0.100 \pm 0.005 \mathrm{~mm}^{2}, \mathrm{n}=16\right)$.

Contractile responses to potassium chloride, potassium ion-free solution and tetraethylammonium chloride: Carotid artery strips from stroke-prone SHRs and Wistar-Kyoto normotensive rats developed tension in a concentration-dependent manner upon cumulative addition of $\mathrm{KCl}$ to the tissue bath (Fig. 4, left). The concentration of $\mathrm{KCl}$ that produced a half-maximal increase in tension $\left(E D_{50}\right)$ was significantly lower for vascular strips from stroke-prone SHRs $(20 \mathrm{mM}$ $\mathrm{KCl} ;-\log \mathrm{ED}_{50}=1.29 \pm 0.02, \mathrm{n}=6 \mathrm{~J}$ when compared with that in strips from Wistar-Kyoto normotensive rats $\left(34 \mathrm{mM} \mathrm{KCl} ;-\log \mathrm{ED}_{50}=1.53 \pm 0.04, \mathrm{n}=6\right)$. The time to half of maximal response for contraction in $\mathrm{K}^{+}-$ free solution was significantly shorter in carotid arteries from stroke-prone SHRs ( $51 \pm 2$ minutes, $n=6$ ) when compared with that in arteries from Wistar-Kyoto normotensive rats $(70 \pm 2$ minutes, $n=6$, Fig. 4 , center). In contrast, maximal tension, developed after $125 \mathrm{mM} \mathrm{KCl}$ or a 120 -minute exposure to $\mathrm{K}^{+}$-free solution, was similar in both strains of rats.

Cumulative addition of tetraethylammonium chloride to the muscle bath caused increases in tension in vascular strips from stroke-prone SIIRs $(n=6)$ and Wistar-Kyoto normotensive rats ( $\mathrm{n}=6$ ] (Fig. 4, right). Stroke-prone SHRs (threshold value $=2.5 \times 10^{-4} \mathrm{M}$; $\log$ threshold value $=3.61 \pm 0.18$ ) were more sensitive to the effects of tetraethylammonium chloride than Wistar-Kyoto normotensive rats [threshold value $=9.8$ $\times 10^{-3} \mathrm{M} ;-\log$ threshold value $=2.01 \pm 0.09, \mathrm{n}=6$ ) .

Contractile responses to $124 \mathrm{mM} \mathrm{KCl}, 120$-minute exposure to $\mathrm{K}^{+}$-free solution and $10^{-1} \mathrm{M}$ tetraethylammonium chloride were virtually abolished in $\mathrm{Ca}^{++}$. free solution containing $1 \mathrm{mM}$ EGTA in carotid arteries from both hypertensive and normotensive rats (Fig. 5). Verapamil $\left(10^{-6} \mathrm{M}\right)$ also markedly attenuated (by $70 \%$ to $80 \%$ ) the contractile responses to all of the stimuli mentioned (Fig. 6). Verapamil had a similar effect on hypertensive and normotensive rats.

\section{Discussion}

This study provides evidence that increased vascular reactivity to depolarizing stimuli in hypertension is due to an alteration in the delivery of activator $\mathrm{Ca}^{++}$ through cell membrane channels. Carotid artery strips from stroke-prone SHRs were more sensitive to the contractile effects of elevated $\mathrm{K}^{+}$and to the $\mathrm{K}^{+}$channel blocker tetraethylammonium chloride than strips from Wistar-Kyoto normotensive rats. The rate of tension development in carotid arteries from strokeprone SHRs placed in $\mathrm{K}^{+}$-free solution was faster than that in arterial strips from Wistar-Kyoto normotensive rats. Contractile responses of arterial strips to all 3 experimental interventions were inhibited by incubation in $\mathrm{Ca}^{++}$-free solution and by the calcium channel blocker verapamil. Although previous studies have demonstrated an increased vascular reactivity to elevated $\mathrm{K}^{+}$concentration, $\mathrm{K}^{+}$-free conditions and many other constrictor stimuli, ${ }^{2}$ to our knowledge this is the
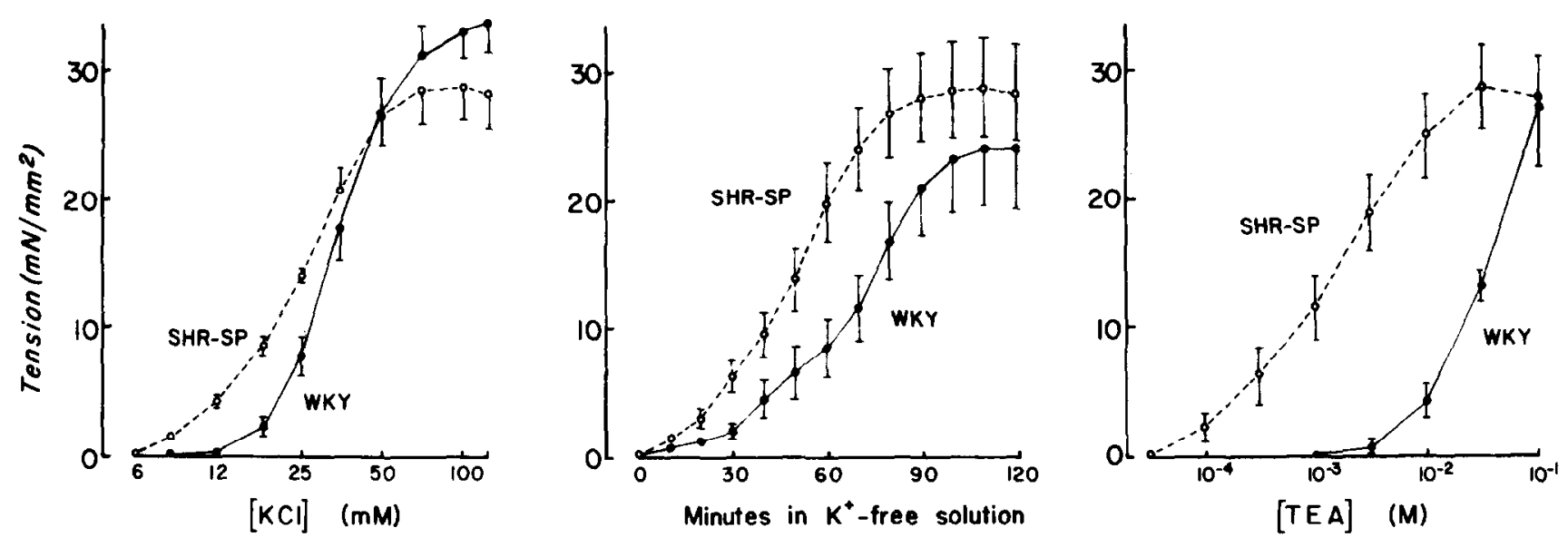

FIGURE 4. Vascular responses to elevated potassium (KCI), $K^{+}$-free solution and tetraethylammonium chlorlde (TEA). Carolld artery strips from stroke-prone spontaneously hypertensive rats (SHR-SP) were more sensitlve to the contractile effects of KCl and tetraethylammonium chloride and contracted faster in response to $K^{+}$-free solution than arterial segmenis from Wistar Kyoto (WKY) normotensive rats. Values are mean \pm standard error of the mean for 6 SHR-SP and 6 WKY normotensive rats. 
first time that a greater sensitivity to tetraethylammonium chloride has been described.

Elevations in extracellular $\mathrm{K}^{+}$concentration produce membrane depolarization due to a reduction in the transmembrane gradient for the ion. ${ }^{15}$ In contrast, membrane depolarization in response to $\mathrm{K}^{+}$-free solution is caused by blockade of the electrogenic sodium pump $^{15}$ whereas tetraethylammonium chloride produces depolarization by inhibition of $\mathrm{K}^{+}$channels. ${ }^{16}$ The observations of the current experiments indicate that the sensitivity to all 3 depolarizing stimuli is increased in carotid arteries from stroke-prone SHRs compared with Wistar-Kyoto normotensive rats. It seems likely that the primary membrane abnormality relates to a change in the relation between membrane potential and the opening of membrane channels for $\mathrm{Ca}^{++}$. Altered regulation of potential-operated $\mathrm{Ca}^{++}$ channels in arteries from stroke-prone SHRs could contribute to the reduced threshold to tetraethylammonium chloride, the reduced $\mathrm{ED}_{50}$ values for $\mathrm{K}^{+}$and the faster rate of tension development to $\mathrm{K}^{+}$-free incubation. Because maximal tension development to all 3 stimuli was not greater in arteries from stroke-prone SHRs compared with that in arteries from Wistar-Kyoto normotensive rats, it seems that the number of calcium channels that can be opened by a maximally effective depolarizing stimulus is not altered in arteries from stroke-prone SHRs. This speculation is strengthened by the observation that $\mathrm{Ca}^{++}$-free conditions eliminated contractile responses to all 3 stimuli in arteries from both stroke-prone SHRs and Wistar-Kyoto normotensive rats.

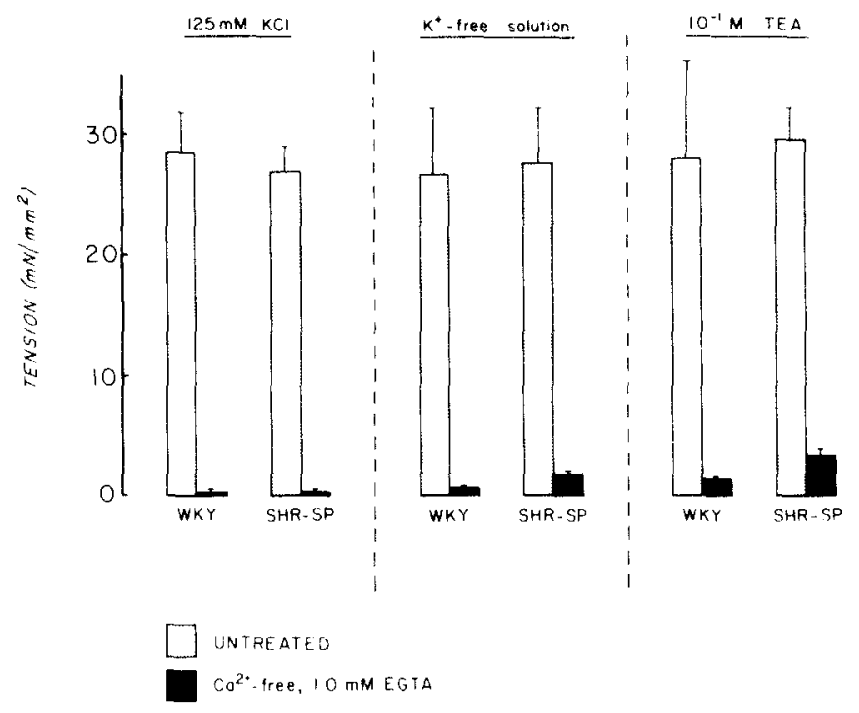

FIGURE 5. $\mathrm{Ca}^{++}$-free solution and contractile responses to elevated $\mathrm{K}^{+}, \mathrm{K}^{+}$-free solution and tetraethylammonium chloride (TEA). Contractile responses in carotid artery strips from stroke-prone spontaneously hypertensive rats (SHR-SP) and Wistar Kyoto (WKY) normotensive rats to $125 \mathrm{mM} \mathrm{KCl}, \mathrm{K}^{+}$-free solution and $10^{-1} \mathrm{M}$ tetraethylammonium chloride were inhibited when strips were placed in $\mathrm{Ca}^{++}$-free solution containing $1.0 \mathrm{mM}$ EGTA. Values are mean \pm standard error of the mean for 4 SHR-SP and 4 WKY rats.
There is a noteworthy characteristic of the doseresponse curves for tension development to tetraethylammonium chloride in carotid arteries from strokeprone SHRs. The threshold sensitivity to tetraethylammonium chloride was approximately 40 times lower in carotid arteries from stroke-prone SHRs compared with that in arteries from Wistar-Kyoto normotensive rats, whereas sensitivity to $\mathrm{K}^{+}$ion was increased by only a factor of 2 in carotid arteries from stroke-prone SHRs. Because tetraethylammonium chloride produces membrane depolarization by blocking $\mathrm{K}^{+}$channels, these observations suggest that the enhanced sensitivity to tetraethylammonium chloride may relate to altered membrane permeability to the monovalent ion. ${ }^{16}$ Indeed, several studies have described increased membrane permeability to $\mathrm{K}^{+}$in vascular smooth muscle from hypertensive animals. ${ }^{17}$ Alternatively, tetraethylammonium chloride may influence $\mathrm{Ca}^{++}$conductance directly ${ }^{16,18}$ and this effect may be altered in vascular smooth muscle from strokeprone SHRs. The greater enhancement of the sensitivity to tetraethylammonium chloride relative to other depolarizing stimuli in hypertension is analogous to that of an enhanced receptor-mediated contraction induced by serolonin relative lo uther agents. ${ }^{19}$ Vascular sensitivity to serotonin is enhanced to a greater degree in blood vessels from mineralocorticoid hypertensive rats than that to norepinephrine and angiotensin II. ${ }^{19}$ The precise mechanisms responsible for relatively greater enhancement of constrictor responses to tetraethylammonium chloride and serotonin are unclear at the present time.

Current evidence supports the view that increased vascular reactivity in hypertension relates to an alter-

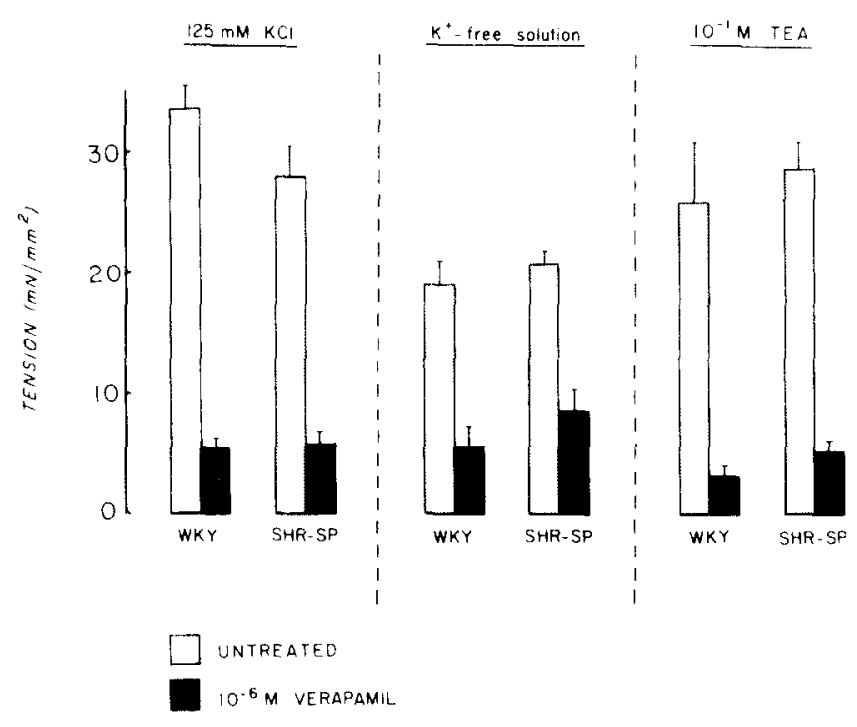

FIGURE 6. Verapamil and contractile responses to elevated $\mathbf{K}^{+}, \mathbf{K}^{+}$free solution and tetraethylammonium chloride (TEA). Contractile responses to these 3 depolarizing stimuli in carotid artery strlps from stroke-prone spontaneously hypertensive rats (SHR-SP) and Wistar Kyoto (WKY) normotensive rats were inhibited by $10^{-6} \mathrm{M}$ verapamil. Values are mean \pm standard error of the mean for 5 to 6 SHR-SP and 4 to 6 WKY rats. 
ation in the transmembrane movement of $\mathrm{Ca}^{++}$. This article characterized an increased sensitivity to depolarizing stimuli in arteries from rats with genetic hypertension. Because the contractile responses were blocked by verapamil and were absent in strips treated with $\mathrm{Ca}^{++}$-free solution, it appears that contraction to the 3 depolarizing stimuli required external $\mathrm{Ca}^{++}$. We conclude that in hypertension there is a generalized increase in sensitivity to depolarizing stimuli and a specific alteration in the membrane events that mediate the agonistic action of tetraethylammonium chloride.

\section{References}

1. Folkow B. Physiological aspects of primary hypertension. Physiol Rev 1982;62:374-427.

2. Webb RC. Vascular changes in hypertension. In: Antanaccio MJ, ed. Cardiovascular Pharmacology. New York: Raven Press, 1984:215-255.

3. Seidel CL. Regulation of vascular smooth muscle contraction. Fed Proc 1984:43:2390-2398.

4. Mulvany MJ, Nyborg N. An increased calcium sensitivity of mesenteric resistance vessels in young and adult spontaneously hypertensive rats. $\mathrm{Br}$ I Pharmacol 1980;71:585-596.

5. Mulvany MJ, Korsgaard N, Nyborg N. Evidence that the increased calcium sensitivity of resistance vessels in spontaneously hypertensive rats is an in trinsic defect of their vascular smooth muscles. Clin Exp Hypertens 1981;3: 748-751.

6. Bohr DF, Harris AL, Guthe CC, Webb RC. Hypertension: multiple membrone malfunctions. In: Villarreal H, Sambi MP, eds. Topics in Pathophysiology of Hypertension. Amsterdam: Martinus Nijhoff, 1984:100-111.

7. Myers JH, Lamb FS, Webb RC. Norepinephrine-induced phasic activity in tail arteries from spontaneously hypertensive stroke-prone rats. Am / Physiol 1985;248: $\mathrm{H} 419-\mathrm{H} 423$

8. Lamb FS, Myers JH, Hamlin MN, Webb RC. Oscillatory contractions in tail arteries from genedically hypertensive rats. Hypertension 1985;7suppl I
$25-30$.

9. Aoki K, Asano M, Sato K, Kondo S, Mochizuki A, Kawaguchi Y, Yamamoto $\mathrm{M}$. Calcium antagonists on the vascular smooth muscle of spontaneously hypertensive rat and human essential hypertension: a calcium membrane theory of essential hypertension. In: Bevan IA, cd. Vascular Ncurocffector Mechanisms: 4th International Symposium. New York: Raven Press, 1983 295-299.

10. Lederballe Pedersen O. Mikkelsen E. Anderson KE. Effects of extracellular calcium on potassium and noradrenaline induced contractions in the aorto of spontaneously hypertensive rats-Increased sensitivity to nifedipine. Acto Pharmacol Toxicol 1980:43:137-144.

11. Nyborg NC, Mulvany MJ. Lack of effect of anti-hypertensive treatment with felodipine on cardiovascular structure of young spontaneously hypertensive rats. Cardiovasc Res 1985;19:528-536.

12. Aoki K. Sato K, Kawaguchi Y. Increased curdiovascular responses to norepinephrine and calcium antagonists in essential hypertension compared with normotensive in humans. I Gardiovasc Pharmacol 1985;7:suppl 6:S182S186.

13. Furspan PB, Lamb FS, Ross PV, Webb RC, Bohr DF. Calcium and vascular smooth muscle membrane in hypertension. In: Tulenko TN, Cox $\mathrm{BH}$, eds. Recent Advances in Arterial Disease: Atheroslerosis. Hypertension and Vasospasm. New York: Alan R. Liss, Inc. 1986:225-243.

14. Vanhoutte PM, Verbeuren TJ, Webb RC. Local modulation of the adre nergic neuroeffector interaction in the blood vessel wall. Physiol Rev 1981;61:151-247.

15. Anderson DK. Cell potential and the sodium-potassium pump in vascular smooth muscle. Fed Proc 1976;35:1294-1297.

16. Haeusler G, Thorens S. Effect of tetraethylammonium chloride on contractile, membrane and cable properties of rabbit artery muscle. I Physiol 1980;303:203-224.

17. Jones AW, Dutta P, Garwitz ET. Altered active and passive transport in vascular smooth muscle during experimental hypertension. In: International Symposium on Cell Membrane in Function and Dysfunction of Vascular Tissue. Goodfriend T, Mever P, eds., Biomedical Press, Elsevier/North Hol land 1981:192-202.

18. Haeusler G, Kuhn H, Thorens S. The effect of tetraethylammonium chloride on calcium fluxes in smooth muscle from rabbit main pulmonary artery. / Physiol 1980;303:225-241.

19. Webb RC, Bohr DF. The membrane of the vascular smooth muscle cell in experimental hypertension and its response to serotonin. In: Stephens N, ed. Smooth Muscle Contructions. New Yurk: Murcel Dekker, 1984:485-508. 